\title{
Código ético de quinto semestre de psicología
}

\author{
Aidee Balderas Ortega \\ Juan Pablo Castillo González \\ Krystel Escamilla López \\ Denise González Álvarez \\ Rodrigo Alejandro Jiménez Estrada \\ Claudia Juárez Cervantes \\ Francisco Javier Larios Meza \\ Rafael Manzano Del Castillo \\ María Vianney Martínez Sánchez \\ Nancy Valeria Meraz Castillo \\ José Miguel Perezgrovas Martínez \\ Marco Antonio Trejo Meza \\ Leonel Villaverde García
}

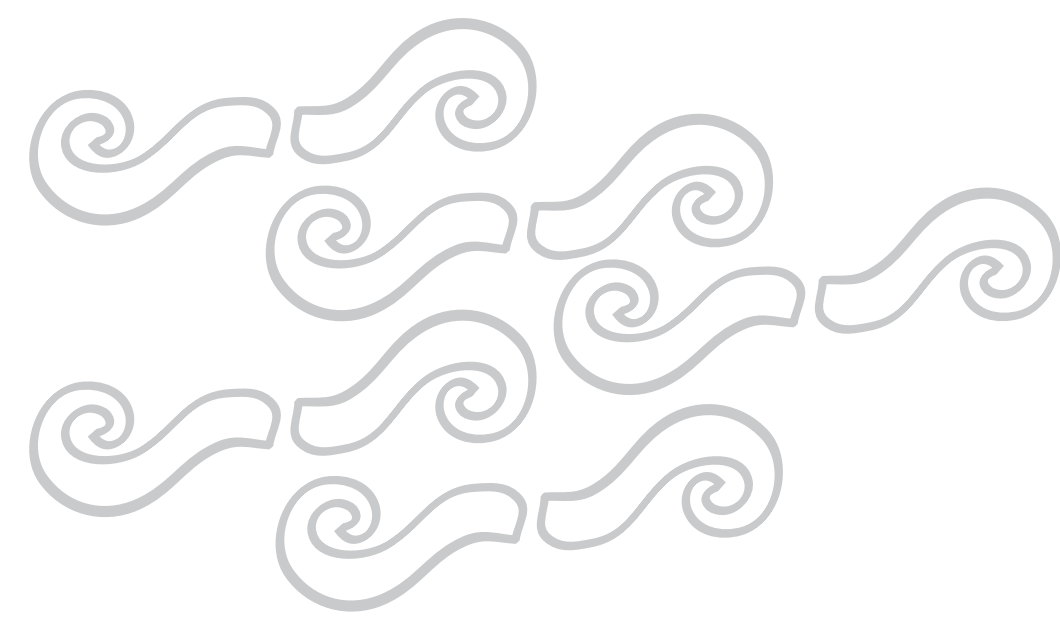

\section{PRESENTACIÓN}

Este es uno de los trabajos que los alumnos de quinto semestre de psicología realizaron en su curso de Ética Profesional. No es un código ético profesional, nunca pretendió serlo. Es, más bien, una exposición ordenada de los deseos morales que afloraron naturalmente al entrar en contacto con la realidad de la práctica psicológica clínica ${ }^{1}$ en instituciones del Estado de Hidalgo

Esta redacción sirve para que los alumnos se confronten dinámicamente en el transcurso de su carrera y en su desempeño profesional con esta declaración de voluntades. El acuerdo y el reconocimiento de lo que no se debe hacer es un punto de partida para la reflexión ética en el campo profesional. Estas bases son las que justamente fundamentan este "código ético". Reconocer en este tipo de declaraciones su carácter de nunca terminadas es lo que las puede convertir en auténticas normas de conducta para la vida personal y profesional.

La publicación no tiene otro motivo que lo que la misma palabra indica, hacer público, compartir con el resto de la comunidad universitaria y de la sociedad, lo que se entiende en este momento concreto de la carrera universitaria, que debe ser el compromiso profesional con la sociedad.

No se debe buscar rigor estricto ni ético ni psicológico en la exposición. Muchas páginas pudieran escribirse como matizaciones y desarrollos técnicos a los distintos artículos. Pero lo que aquí podemos leer no es de carácter formal, sino material, es decir, no es el enunciado de principios universales, sino de realidad vivida y de compromiso presente y futuro.

\section{Contenido}

El Código de Ética Profesional tiene como función sensibilizar al profesionista para que su ejercicio profesional se desenvuelva en un ámbito de honestidad, legitimidad y moralidad a beneficio de la sociedad. El cumplimiento del código depende exclusivamente de la voluntad de quien se ha impuesto por sí mismo el deber de cumplirlo.

Toda acción que lleve acabo un psicólogo en relación a un paciente debe tomar como punto de partida el hecho de que su trabajo es dirigido hacia la mejora de un ser humano, por lo tanto, tiene el deber de conservar la integridad de éste tomando en cuenta todo lo que engloba la integridad y bienestar de un ser humano. 


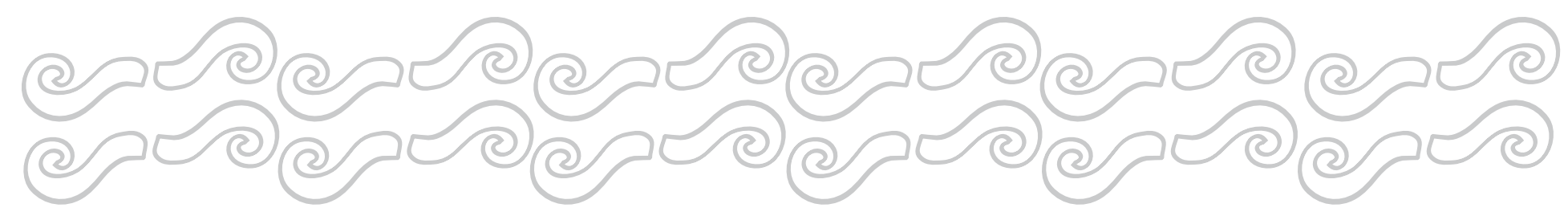

El psicólogo debe promover la dignidad humana y los derechos de las personas a través de la aceptación de las diferencias individuales, sociales y culturales, evitando imponer las propias con la finalidad de que la relación sea más humana.

\section{Formación profesional}

1. El psicólogo debe estar consciente de la importancia de tener una formación, tanto académica como personal, suficiente para poder prestar sus servicios en cualquier área en la que se quiera desenvolver, para poder desempeñarse con mayor seguridad y responsabilidad en su trabajo.

2. Como parte de la formación de un psicólogo, consideramos de suma importancia que éste se someta, por lo menos, a un proceso terapéutico durante su formación en licenciatura, para que a partir de ello se vuelva un deber constante a lo largo de su práctica profesional. Eso es necesario para evitar que sus problemas personales interfieran con su trabajo, además le ayudaría a crear una mejor empatía con las personas que utilizan su servicio, debido a que él sabría lo fácil o difícil que es exponer su situación de vida a manera de experiencia.

3. Es necesario que el psicólogo se actualice para asegurar un mejor aprovechamiento de sus capacidades en la ejecución de sus deberes, por lo que es de suma importancia que el psicólogo esté en un proceso de aprendizaje continuo, ya que eso le permitirá estar al tanto en conceptos, temas, pruebas, técnicas, entre otras cosas y así poder ofrecer un servicio de calidad.

4. El psicólogo no debe atribuirse grados académicos que no le correspondan. Debe ser honesto con los servicios que presta, por lo que debe aclarar el grado académico que tiene sin atribuirse lo que no posee.

5. El psicólogo, sin importar el área ni la corriente, debe saberse limitado tanto en su conocimiento como en su práctica y ser lo suficientemente humilde para pedir y aceptar la ayuda de otros profesionales en casos específicos. Debe asesorarse, pedir consejo a otro profesional, protegiendo la identidad de sus pacientes. Debe respetar y nunca minimizar el trabajo y formación de sus colegas que tengan otra área de desempeño o corriente psicológica como base, ya que todas tienen límites que en algún momento pueden ser complementadas.

6. Para prestar un mejor servicio es preferible que el psicólogo tenga un campo especializado de conocimiento y práctica, dentro del cual esté perfectamente bien informado e instruido, de tal manera que no exista posibilidad de no saber cómo atender un caso de ese campo.

7. La lectura debe ser hábito de todo psicólogo, ya que esto le dará herramientas e información profesional y cultural para enriquecerse. El leer permite al sujeto estar en continua adquisición de conocimiento nuevo y permite cuestionar lo aprendido previamente, o, lo ya establecido. Este hábito también ofrece, en el caso del terapeuta, la posibilidad de tener un mayor entendimiento con el paciente ya que existe una posibilidad más amplia de que conozca del tema o temas de su interés.

8. Es deber del terapeuta conocer las normas jurídicas y los estatutos legales relacionados a su práctica, en primer lugar para desarrollar un justo desempeño de su profesión y en segundo lugar para proteger a las personas que acudan a él solicitando un servicio. 


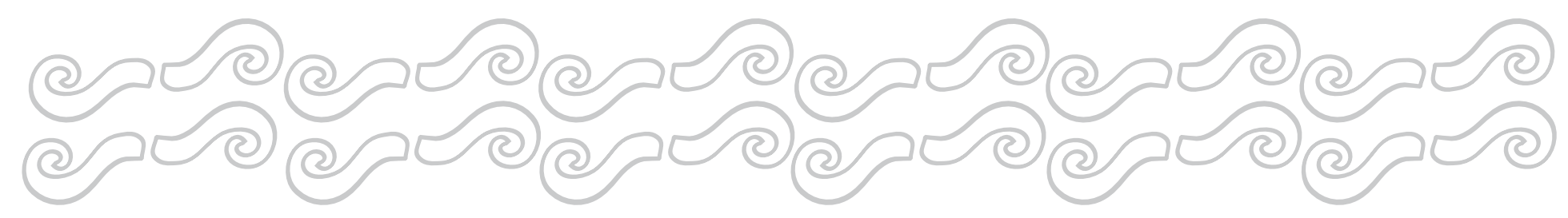

\section{Práctica profesional}

1. El psicólogo debe mantener buena voluntad y actitud con cada paciente con el que trabaje, así como buena disposición y la capacidad de discernir lo que pueda referir o hacer el paciente, de igual forma mantener un pensamiento y actitud positiva, ya que eso lo llevará a tomar decisiones pertinentes para la mejora del paciente.

2. La relación profesional en la práctica privada con un paciente es voluntaria, por lo que el pa ciente puede discontinuar el tratamiento o buscar otro en cualquier momento del proceso terapéutico.

3. En terapia, el psicólogo debe trazarse los límites hasta donde puede llegar a ayudar a la persona, ya que debe de tener en claro la obligación de atender el desarrollo de la persona pero también debe dejar en manos del paciente todo aquello que pueda realizar por sí mismo, porque es importante que la persona sea un agente activo para su propio desarrollo y no tratarla como un objeto.

4. El psicólogo debe garantizar un trato humano, proporcionando un ambiente de confianza, compromiso y respeto mutuo, por lo que es obligación del psicólogo dejar a un lado sus prejuicios.

5. El psicólogo debe estar consciente de las diferencias individuales y no discriminar por edad, género, nivel económico, política y cultura, respetando también las creencias religiosas e ideológicas de sus pacientes, ya que hay que tomar en cuenta que el hombre es un ser cultural que posee aprendizajes, actitudes, creencias, costumbres y tradiciones de una sociedad debido a que cada persona se ha desarrollado en un medio ambiente diferente.

6. El psicólogo no debe hacer juicios o críticas hacia la forma de vida de un paciente ni de los resultados o interpretaciones que obtenga a lo largo de las actividades realizadas con éste, debido a que se deben respetar las capacidades y actos de cada persona así como la libertad que ésta tiene para decidir, escoger o elegir (autonomía que cada persona posee).

7. En un ambiente en el que se busca auxiliar a una persona que necesita ayuda, el psicólogo debe respetar la intimidad de la persona que utiliza sus servicios y la confianza que éste deposita en él, asegurándole un ambiente discreto. Los psicólogos tienen el deber de conservar en secreto todo cuanto observen, escuchen o descubran en el ejercicio de su profesión, así como mantener bajo resguardo la información de cada paciente, con excepción de que su servicio haya sido solicitado para fines legales o que el paciente autorice que su caso sea expuesto.

8. El psicólogo debe garantizar su dedicación en cada caso, dándole la importancia pertinente, llevando una historia clínica escrita de cada uno de sus pacientes y registrando la evolución constante de los mismos. La información que el psicólogo recopile y documente, debe llevar y mantener un orden para poder identificar claramente la afección de cada paciente y poder dar más aportes a su caso y dar el seguimiento adecuado que requiere cada paciente.

9. El psicólogo debe reconocer sus limitaciones, por lo tanto, transferir a un especialista los casos para los cuales no tenga la suficiente capacitación.

10. El psicólogo debe ser responsable y asistir a todas sus citas de manera puntual, en caso de que no pueda asistir a alguna cita debe informarle a la persona que utiliza sus servicios con anticipación y reprogramarla lo antes posible. 


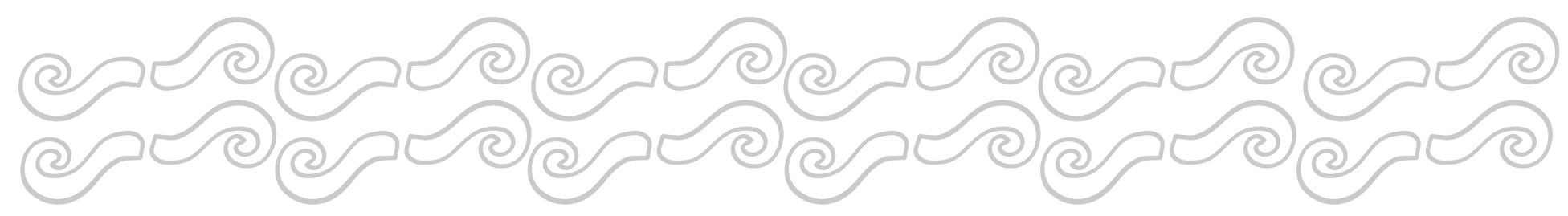

11. En un tratamiento psicoterapéutico, el psicólogo debe de prestar toda su atención a la sesión que se está llevando acabo, tomando en cuenta la puntualidad del psicólogo y la total disposición de su paciente.

12. El psicólogo deberá asumir una postura de responsabilidad con la sociedad en todo lo que haga, incluyendo el hecho de aceptar errores así como estar totalmente comprometido en sentido terapéutico.

13. Al realizar evaluaciones o diagnósticos, el psicólogo deberá ver ante todo por la integridad, interés y bienestar del paciente. Respetando la dignidad de las personas, además de respetar el derecho del usuario a conocer los resultados y las interpretaciones que se le han dado. Evitar que personas sin formación o preparación adecuada hagan uso inadecuado de las técnicas de evaluación.

14. El psicólogo debe asegurarse de adecuar su lenguaje de manera que sea entendible para su paciente al momento de darle su valoración y comunicar los resultados de ésta.

15. El psicólogo evitará cualquier tipo de técnica de valoración indebida, así como inventar datos y falsificar resultados de investigaciones realizadas.

16. Los honorarios y arreglos financieros serán expuestos y aceptados por el paciente en la terapia psicológica o en el caso de un ajuste de honorarios, deberán ser anunciados previo a su implementación. El psicólogo no deberá tener relación financiera con el paciente a excepción de los honorarios de las terapias. El psicólogo se abstiene de aceptar bienes, servicios u otros favores personales para sí mismo o para parientes o amigos cercanos, por parte de pacientes o clientes, a cambio de servicios psicológicos, porque tales arreglos llevan el potencial inherente para crear conflictos, explotación, o distorsión de la relación profesional.

17. El psicólogo deberá estar consciente de su situación personal tanto mental como física. En el caso de no ser capaz de prestar algún servicio por alguna limitación que pueda padecer, el psicólogo no deberá tomarlo. El psicólogo debe de reconocer cuando algún problema o conflicto personal esté interfiriendo con su efectividad.

18. El psicólogo nunca provoca o se insinúa sexualmente ni se involucra en situaciones de acoso sexual hacia sus pacientes, estudiantes o supervisados en proceso de capitación sobre los cuales tienen autoridad directa o de evaluación, aunque ellos lo permitan o estén de acuerdo.

19. El psicólogo debe tener siempre presente sus limitaciones y saber reconocer cuando éste no puede ayudar al paciente. Sólo proporcionarán servicios para los cuales están capacitados de acuerdo a su experiencia. En caso contrario de que no pueda atender a dicho paciente, deberá canalizarlo en base a los mejores intereses del mismo y no engañar a la persona ofreciéndole una ayuda que no podrá ofrecer.

20. La práctica irresponsable de un psicólogo debe ser denunciada por sus colegas. El psicólogo debe exponer la conducta corrompida o incompetente de otro miembro de su profesión debido a que éste tiene un compromiso con el paciente, con los familiares y la sociedad en general promoviendo la salud mental y el desarrollo integral de las personas. 


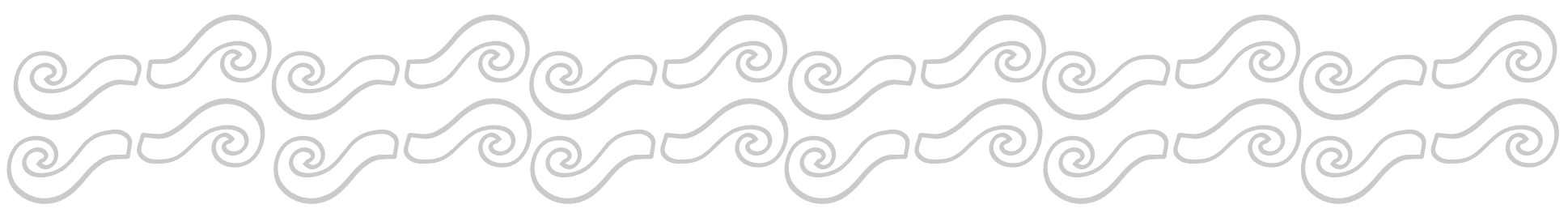

En el campo de la investigación experimental

1. El psicólogo en su labor experimental de las investigaciones de campo debe ser consciente de su entorno, cuidarlo, no dañarlo y debe tratar de preservar el ambiente tal y como está, por lo tanto, el psicólogo debe respetar a cada uno de los seres vivos que componen el medio ambiente.

2. El psicólogo en el campo experimental debe respetar la dignidad de las personas que utiliza como sujeto de estudio. Por ninguna razón debe poner en riesgo la vida del individuo, integridad física o mental.

3. El psicólogo en el campo experimental al exponer los resultados de su trabajo debe fundamentarlos, describiendo de manera correcta la procedencia de sus citas, así como también debe reconocer el trabajo realizado por sus colaboradores, evitando exponer como suyas las ideas de otros investigadores.

\section{Conclusión 0@}

Realmente en este trabajo no hay punto final. La intención es seguir completando esta declaración con nuevas experiencias vitales de la práctica psicológica que los redactores de la misma vayan teniendo en el transcurso del tiempo. Esta labor tendrá que concluir cuando ya no exista más el ejercicio de asomarse al insondable misterio de la persona.

1 Área que corresponde a los intereses de los alumnos.

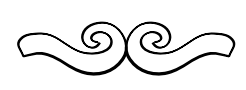

